\title{
Escola Pública e Projeto Social: o cotidiano das aulas de Capoeira
}

\author{
Escuela Pública y Proyecto Social: el cotidiano de las clases de Capoeira \\ Public School and Social Project: the daily life of Capoeira classes
}

\author{
Alex dos Santos Gorito ${ }^{1}$ \\ Marcelo Paraiso Alves ${ }^{2}$
}

\begin{abstract}
Resumo
O presente trabalho tem como centralidade a prática da Capoeira no Programa Arte, Educação e Cidadania que está localizado na Cidade de Barra do Piraí-RJ. Considerando o impacto desta prática corporal no cotidiano dos estudantes que participam do projeto investigado, cabe refletir: Quais as contribuições da Capoeira para os sujeitos participantes? O objetivo do estudo foi investigar as possíveis contribuições das práticas socioculturais desenvolvidas pela Capoeira no referido programa, desenvolvido junto à comunidade da Chacrinha, município de Valença-RJ. Metodologicamente, optamos pelos Estudos do Cotidiano, pelo fato de mergulharmos nas práticas dos estudantes que participam do referido projeto. Utilizamos como instrumentos para produção de dados a roda de conversa e o diário de bordo, no intuito de apreender os registros, acontecimentos e modos comportamentais por meio de observações, que só se tornam possíveis mediante a participação cotidiana nas aulas de Capoeira. Considerando ser esta, uma pesquisa com estudantes, este trabalho foi aprovado com o parecer 2.168.033 e o CAAE 69443417.4.0000.5237 pelo comitê de ética de pesquisa do Centro Universitário de Volta Redonda. Os resultados revelam que o Projeto Capoeira resgata as raízes históricas, facilita o acesso à cultura corporal, fortalece as relações em grupo, mostra que os estudantes, ao adotarem valores na roda de Capoeira, modificaram seus comportamentos em outros espaços de sociabilidade.
\end{abstract}

Palavras-chave: Capoeira; Cotidiano; Escola.

\section{Resumen}

El presente trabajo tiene como centralidad la práctica de la Capoeira en el programa arte, educación y ciudadanía que se encuentra en la ciudad de Barra do Piraí-RJ. Considerando el impacto de esta práctica corporal en la vida diaria de los estudiantes que participan en el proyecto investigado, vale la pena reflexionar: ¿Cuáles son las contribuciones de la Capoeira a los sujetos participantes? El objetivo del estudio fue investigar las posibles aportaciones de las prácticas socioculturales desarrolladas por la Capoeira en dicho programa, desarrollada junto a la comunidad de Chacrinha, ubicada en el municipio de Valença-RJ. Metodológicamente, optamos por los Estudios del Cotidiano, por el hecho de sumergirse en las prácticas de los estudiantes que participan en dicho proyecto. Utilizamos como instrumentos para la producción de datos la rueda de conversación y el cuaderno de campo, con el fin de aprehender los registros, acontecimientos y modos comportamentales por medio de observaciones, que sólo se hacen posibles mediante la participación cotidiana en las clases de Capoeira. Considerando que está, una investigación con los estudiantes, este trabajo ha sido aprobado con la opinión 2.168.033 y la CAAE 69443417.4.0000.5237 por el Comité de ética de la investigación del Centro Universitario de la ronda. Los resultados demuestran que el proyecto de Capoeira rescata raíces históricas, facilita el acceso a la cultura corporal, fortalece las relaciones grupales, muestra que los estudiantes al adoptar valores en la Capoeira, modifican sus comportamientos en otros espacios de sociabilidad.

Palabras clave: Capoeira; Diaria; Escuela.

\footnotetext{
${ }^{1}$ Mestrando em Ensino em Ciências da Saúde e do Meio Ambiente; Centro Universitário de Volta Redonda UniFOA; Volta Redonda, Rio de Janeiro, Brasil; alexsgorito@gmail.com.

${ }^{2}$ Doutor em Educação; Centro Universitário de Volta Redonda - UniFOA; Instituto Federal do Rio de Janeiro IFRJ; Volta Redonda, Rio de Janeiro, Brasil; marceloparaiso@outlook.com.
} 


\begin{abstract}
The present work has as its centrality the practice of Capoeira in the Art, Education and Citizenship Program, which is located in the city of Barra do Piraí. Considering the impact of this corporal practice on the daily life of the students who participate in the research project, it is necessary to reflect: What are the contributions of Capoeira to the participants? In the above view, the objective of the study was to investigate the contributions of the socio-cultural practices developed by Capoeira inserted in the program Art, Education and Citizenship developed next to the community of Chacrinha, in the city of Valença- RJ. Methodologically, we opted for Daily Life Studies, due to the fact that we immerse ourselves in the practices of students participating in the project. We use as instruments for the production of data the conversation wheel and the logbook, in order to apprehend the registers, events and behavioral modes through observations, which are only possible through daily participation in Capoeira classes. Considering being, a research with students, this work was approved with the opinion 2,168,033 and the CAAE 69443417.4.0000.5237 by the Research Ethics Committee of the University Center of round. The results show that the Capoeira project rescues historical roots, facilitates access to body culture, strengthens group relationships, shows that students when adopting values in the Capoeira, modify their behaviors in other spaces of sociability.
\end{abstract}

Key words: Capoeiragem; Everyday; School

\title{
1. Introdução
}

O presente estudo possui como centralidade a prática da Capoeira em um projeto social desenvolvido no município de Barra do Piraí-RJ. A investigação se justifica por três questões complementares: primeiro, pela relevância da roda de Capoeira como um patrimônio cultural brasileiro desde 2008, descrito no portal do Instituto do Patrimônio Histórico e Artístico Nacional (IPHAN); segundo, seu reconhecimento, a partir de 2014, como patrimônio cultural imaterial da humanidade da United Nation Educational, Scientific and Cultural Organization (UNESCO) (PERTUSSATTI, 2017); e terceiro, pela memória ritualística das culturas afro-brasileiras que resguarda a memória coletiva da ancestralidade, a partir da experiência cíclica dos rituais e relação de pertencimentos aos grupos sociais (GUIMARÃES, 2012).

Assim, a relevância desta pesquisa parte da constatação de que a referida cultura corporal de movimento está presente em mais de 150 países com um grande potencial de divulgação da língua portuguesa, e possibilitando a emergência da diversidade de ações e utilizações pelos seus praticantes, tornando-a um fenômeno a ser investigado fundamentalmente a partir das experiências locais (CONDE, 2007).

Outro aspecto que contribui para a relevância do estudo se reveste dos direitos à cultura (PORTAL DA CULTURA), pois conforme proclamado pela UNESCO, na convenção sobre a Proteção e Promoção da Diversidade das Expressões Culturais da Conferência Geral em Paris, as tradições culturais são fatores importantes, que possibilitam aos sujeitos e a população exteriorizarem e dividirem com as pessoas seus pensamentos e costumes. Neste documento, a UNESCO defende que a cultura é um dos elementos fundamentais do 
desenvolvimento e que, os aspectos culturais são tão importantes quanto os seus aspectos econômicos, e em decorrência, os indivíduos e as sociedades possuem o direito fundamental de participarem e se beneficiarem das expressões que dela emergem.

Assim, pensando na importância da Capoeira e, no impacto desta prática corporal, no cotidiano dos sujeitos que participam do Programa Arte, Educação e Cidadania, e nas experiências obtidas ao longo de oito anos com as aulas desta cultura corporal, ficamos a refletir: quais as contribuições da Capoeira no referido programa? Quais as influências promovidas pela Capoeira na comunidade de Chacrinha?

Diante do exposto o objetivo do estudo foi investigar as possíveis contribuições das práticas socioculturais desenvolvidas pela Capoeira no programa. Como ações específicas a pesquisa se propõe as seguintes: identificar o papel da Capoeira no programa; discutir a ritualística da Capoeira e investigar as mudanças comportamentais dos estudantes que participam do projeto, na roda.

Para finalizar, torna-se relevante explicitar que a Capoeira desenvolvida no Programa Arte, Educação e Cidadania centraliza suas ações em uma perspectiva contemporânea, sendo está definida pela "mistura da Capoeira Angola e Regional conjugada com elementos característicos das práticas corporais modernas" (DE ALMEIDA; TAVARES; SOARES, 2012, p. 377).

\section{Metodologia}

Esta pesquisa se desenvolveu por meio dos Estudos do Cotidiano, mais especificamente viabilizada pela ótica da Pesquisa com o Cotidiano de Ferraço (2007). Para o autor, tal perspectiva não aceita o distanciamento entre sujeito e objeto, visto que a ação do professor está enredada ao movimento do pesquisador proporcionando uma produção a partir da noção de rede de fazersaberes ${ }^{3}$, na qual o conhecimento é tecido como fio em um tear partilhado pelos sujeitospraticantes (ALVES, 2001).

Diante do exposto e dos pressupostos metodológicos da pesquisa 'com' o cotidiano, assumo o lugar de professorpesquisador, a partir de duas questões centrais: primeiro, como docente responsável do Programa Arte, Educação e Cidadania por desenvolver o processo educativo por intermédio da Capoeira, mas que apresenta em sua corporeidade (NAJMANOVICH, 2001), as marcas da experiência como praticante de Capoeira ao longo

\footnotetext{
${ }^{3} \mathrm{~A}$ junção de palavras procede da aproximação das ideias de Alves (2001, p. 66), visto que: "Esse modo de escrever se mostrou necessário para buscar superar a dicotomização herdada no período no qual se 'construiu' a ciência moderna".
} 
dos últimos trinta anos. De outro modo, também evidencio meu lugar de enunciação como professor de Educação Física desde 2011. O segundo aspecto relevante a ser mencionado, emerge da ação como pesquisador a partir do desenvolvimento do projeto de pesquisa vinculado à dissertação de mestrado.

Cabe frisar que, no mergulho investigativo no intuito de pesquisar a minha própria prática, estabeleci uma ação de 'caça e caçador', visto que ao tentar compreender o 'outro', fui me compreendendo: (...) nós nos lemos nos textos dos autores, acreditando, por vezes, que estamos lendo os autores. Assim sendo, nessas leituras de nós mesmos produzimos outros textos, que não são só nossos, mas também daqueles com os quais temos dialogado até então" (FERRAÇO, 2003, p. 166).

Os sujeitos da pesquisa são participantes das aulas de Capoeira, que têm sua centralidade no Centro Cultural Aracy Carvalho Di Biase, localizado na Rodovia Benjamin Lelpo, Km 11, Barra do Piraí. O município está no centro da região Sul Fluminense, fica a uma distância aproximada de $100 \mathrm{~km}$ da cidade do Rio de Janeiro. Sua população é estimada em 96.865,00 habitantes, a economia e composta por agricultura, indústrias metal-mecânicas e pecuária $\left(\mathrm{IBGE}^{\mathrm{A}}\right)$

O programa se estende para cidade vizinha conhecida por Valença. Segundo o IBGE ${ }^{\mathrm{B}}$, esse município tem população de $73.725,00$ pessoas, e a economia encontra se direcionada para agropecuária e no polo universitário sediado no município.

A Capoeira é ofertada aos estudantes do CIEP Costa Júnior, localizado na comunidade Chacrinha, mais especificamente na cidade de Valença e distante do Centro Cultural aproximadamente $30 \mathrm{~km}$. O referido bairro é conhecido como uma comunidade que emerge de uma classe social em vulnerabilidade social.

As aulas acontecem na referida escola às quintas-feiras, tendo início quatorze e término às dezesseis horas. As faixas de idade dos participantes variam entre oito e dezesseis anos, sendo separado por uma turma até onze anos, e outra de doze a dezesseis anos.

Na última sexta-feira de cada mês, as atividades são ministradas no Centro Cultural Aracy Carvalho Di Biase. O transporte é disponibilizado pelo programa, e parte do CIEP (Valença) quatorze horas, tendo retorno às quinze horas e trinta minutos.

Duas vezes por ano os integrantes da Capoeira participam das ações sociais promovidas pela Universidade Geraldo Di Biase. Além destes, surgem eventos de Capoeira nos quais podem ser oferecidos aos sujeitos inseridos nas aulas. Todo deslocamento e lanche são custeados pelo programa. 
Como instrumento investigativo, optamos pelo diário de bordo, dando início as descrições no primeiro semestre de 2017, mais especificamente do dia 09/03/17 a 31/08/2017. E em detrimento deste, os referenciais teóricos Geertz (1989, p. 20), antropólogo americano que se debruça na simbologia das culturas e nos motivos pelos quais esses símbolos podem levar ao entendimento de um meio social. Para tanto o autor sugere um diário para constar registros, acontecimentos reais e modos comportamentais por meio de observações, que só se tornam possíveis mediante a vivência com os nativos de uma região. Deter subjetivamente a tradução que as pessoas emanam de seus atos, é nomeado pelo autor como descrição densa. É caracterizada por "uma apreensão de elementos para apresentação dos mesmos, por meio de entrevistas, observações, deduções, traçar linhas de propriedade, fazer o senso doméstico e escrever". Tal instrumento (diário de bordo) nos auxiliou nas observações obtidas por meio da Pesquisa com o Cotidiano (FERRAÇO, 2007).

Outro instrumento utilizado na pesquisa foi à roda de conversa, pois está configura se, "no âmbito da pesquisa narrativa, uma forma de produzir dados em que o pesquisador se insere como sujeito da pesquisa pela participação na conversa e, ao mesmo tempo, produz dados para discussão" (MOURA; LIMA, 2014, p. 99).

Nesta linha de pensamento, as rodas de conversas ocorriam ao término das aulas de Capoeira, uma vez que a própria dinâmica da Capoeira se desenvolve na roda, solicitávamos aos participantes que se sentassem e daí iniciávamos a conversa a partir de algo que tivesse correlação com os acontecimentos na roda de Capoeira, posteriormente as questões eram anotadas em caderno de campo.

A opção pela utilização da roda de conversa se deu em decorrência da noção de narrativas expressa por Benjamin (1987, p. 201). Para o autor, “O narrador retira da experiência o que ele conta", portanto, ao considerarmos que a roda de Capoeira é cercada por rituais e práticas que emergem das narrativas dos antepassados, concebendo significado à referida cultura corporal de movimento, a experiência, a memória e o ato de narrar adquirem espaço diferenciado no contexto deste estudo.

Metodologicamente outra formulação da roda de conversa ocorreu no dia 21 de outubro de 2017, a partir de um convite intitulado Roda de Capoeira: conversa com café, emitido à escola CIEP Costa Junior, em setembro de 2017, pelo Programa Arte, Educação e Cidadania. $\mathrm{O}$ intuito foi articular uma reunião com pais/responsáveis, professores/funcionários, dos estudantes inseridos no Projeto Capoeira, com o objetivo de apreender as informações necessárias para o desenvolvimento da pesquisa. Aconteceu uma roda para os pais/responsáveis, e outra separadamente, para professores e funcionários da 
escola (CIEP Costa Júnior), cada uma com duração de cinquenta (50) minutos. Ao desenvolver a roda de conversa, utilizamos o auditório da escola, as cadeiras formaram um círculo, nas quais os participantes se sentaram.

\section{Goffman e a fachada social}

No intuito de analisar os dados apreendidos, utilizamos Goffman (2002), antropólogo e sociólogo canadense, que evoca a ideia de que a atividade individual tem significância para outros, mas, é preciso mobilização e interação para torna lá expressiva e passível de transmissão.

Em sua obra, "a representação do eu na vida cotidiana" (GOFFMAN, 2002), aborda o comportamento humano em sociedade e sua forma de manifestação, trazendo o pensamento que o ser humano em seu meio social se apodera das maneiras de representar para existir mediante as outras pessoas.

Na visão do autor, uma pessoa respeitada ou apreciada dentro de uma comunidade, é capaz de promover mudanças nas relações sociais. Para tanto é necessário que haja um trabalho de mediação desenvolvido por tal pessoa, para que a apropriação de certas posturas aconteça. Na concepção de Goffman (2002), até a consolidação desse processo, são utilizadas formas de representação pelos sujeitos que constituem determinado grupo.

Nessa visão, o sociólogo supramencionado utiliza uma ótica da teatralização dos fenômenos sociais como metáfora para estabelecer a relação entre coisas fictícias e o cotidiano.

Para Goulart e Bregunci (1990) a interpretação interacionista estabelecida por Goffman (2002) apresenta a potencialidade dos processos sociais, pois considera que a imagem que tem de si o dirige e o guia, "modelando as imagens de si que são acessíveis aos outros".

Nesta linha de pensamento, Peled (2008) ao se reportar a Goffman (2002) menciona que tais papéis emergem da performance, pois seu caráter cênico permeia as interações humanas. Portanto, neste estudo a performance será concebida pelo modo como uma atividade de um determinado ator social, em um dado momento, de alguma forma, influencia outros sujeitos.

Para Silva (2005) a representação do papel social é influenciada pela plateia, que será determinada, por outro indivíduo ou grupo, estando na posição de interlocutor. Para o autor, esta influência se deve por envolver aspectos de interesses (individual ou coletivo) que estão em jogo. 
A representação é concebida como sendo atividades interpretadas pelas pessoas nas ocasiões em que passam com um grupo específico, no qual de alguma forma buscam influenciar de alguma maneira. Para Amossy (2005, p. 12), a representação seria o "papel (cota) ou de rotina, definidos como o modelo de ação preestabelecido desenvolvido durante uma representação e que se pode apresentar ou utilizar em outras ocasiões".

O elemento apresentado por Goffman (2002, p. 29) que utilizamos para discussão de dados foi à fachada social, esse, “é o equipamento expressivo de tipo padronizado intencional ou inconscientemente empregado pelo individuo durante sua representação”.

Para Salvini, De Souza e Marchi Júnior (2015), o termo fachada refere-se ao lugar onde a representação é executada, onde a cena acontece.

Já Rossini (2013) remete-se a tal conceito na forma de um somatório de elementos pelos quais a platéia identificará a representação do papel social estabelecido no determinado momento pelo ator. Desta maneira, o ator articula uma variedade de elementos "vestimentas, gesticulações, modo de se portar e falar diante de seus interlocutores, conforme aquilo que quer representar" (ROSSINI, 2013 p. 7). Assim, a fachada permite ao ator social escolher os elementos cênicos que compõem o cenário e que permite a sua identificação no grupo.

Para Goffman (2002), há necessidade de existir um cenário composto pelos elementos que influenciarão nas relações coletivas. Esse servirá de ponto de partida para a tomada de decisão dos sujeitos em relação à representação.

Tal termo (fachada social), segundo o autor, ao direcionar as expressões cênicas, pode ser conceituado como uma fachada pessoal, ou seja, passa a se relacionar com os outros elementos que compõem uma expressão e dão particularidades aos atores, como: "vestuário, sexo, idade e características raciais, altura e aparência, atitude, padrões de linguagem, expressões faciais, gestos corporais e coisas semelhantes" (GOFFMAN, 2002 p.31). Possivelmente a fachada pessoal seguirá o ator para onde ele for.

O autor supracitado descreve que uma fachada pessoal pode ser observada mediante a aparência, fato que é relativo à utilidade da informação que é transmitida pelo sujeito, e pela maneira como se desenvolve por intermédio das posturas adotadas pelos indivíduos para se apresentarem diante de uma situação.

Goffman (2002) salienta que por mais particular que seja uma atividade, a fachada social, que são as particularidades de cada grupo, normalmente reivindicará atos concretos quando forem aplicados em práticas de naturezas distintas.

De acordo com o autor supramencionado, grupos pequenos podem apresentar fachadas semelhantes. No entanto, em grandes grupos surgem hierarquias, facilitando as relações entre 
as pessoas, Goffman (2002) exemplifica tais clãs mencionando as fábricas, quartéis e os outros grandes estabelecimentos sociais. Essa hierarquia, na concepção do autor, determina os subgrupos, onde não são usados os mesmos sanitários ou as mesmas cantinas. Esses são separados por categorias, ou linhas, dentro dos grandes grupos.

O parágrafo acima nos possibilita o entendimento dos grandes grupos darem origem aos subgrupos que utilizam a mesma fachada, apesar das diferenças. Esse fato se dá pela institucionalização. Nesse caso, a fachada torna se uma representação coletiva.

A subdivisão também está presente nas fachadas sociais, agrupando se em cenário, aparência e maneira. Nesse aspecto, diferentes atividades são apresentadas sob a mesma fachada. Ao exemplificar, trazemos o cenário de um tribunal, no qual, um advogado ao se apresentar em tal ambiente, com uma aparência, que sobressaia perante as demais, deve utilizar as maneiras e os modos de fazer e expressar, que condizem com tal aparência. Entretanto, há variações nesse contexto, pelas quais podemos perceber que nem sempre uma maneira segue a aparência e vice-versa. Além desse fato, a mesma aparência pode ser apresentada em cenários distintos. $\mathrm{O}$ advogado pode se apresentar em um encontro com os amigos com a mesma roupagem que utilizara em um tribunal (GOFFIMAN, 2002).

\section{A fachada social da roda de Capoeira}

Ao nos debruçarmos sob a teoria da representação de Goffman (2002) observamos a necessidade de esclarecer a fachada que identifica a roda de Capoeira, visto que, serve de ponto de partida para identificar as relações sociais dentro do grupo. Dessa maneira, torna se importante configurar os aspectos cênicos de uma roda de Capoeira: o uniforme, os apelidos, as graduações, os instrumentos (no mundo da Capoeira por orquestra ou bateria, composta, nos dias atuais, predominantemente dentre os grupos, por três berimbaus, Gunga, conhecido por Berra Boi em algumas academias de Capoeira, Médio e Viola, um atabaque, dois pandeiros e um agogô). É possível que haja em determinadas rodas outros instrumentos.

Articulada a orquestra, encontramos as palmas e cantigas, que conduzidos com domínio e harmonia, estabelecem um comportamento necessário para que atualmente haja a construção do jogo de Capoeira na roda.

O uniforme surgiu com a implantação do turismo cultural na Bahia (REGO, 1968). A roupagem seguiu o padrão de vestimenta utilizada pelos negros, capoeiristas ou não, nos domingos, feriados e dias santos, momento em que todos tinham folga. Ao vestir-se davam preferência para cor branca, sendo "calça folgada com boca de sino cobrindo todo o 
calcanhar, camisa comprida, por cima das calças, chagrin e lenço de esguião de seda, envolto no pescoço" (REGO, 1968, p. 43).

De acordo com o autor, anteriormente ao advento do turismo cultural na Bahia, a região do Cais do Porto era local onde trabalhavam os capoeiristas mais famosos, que nos períodos de intervalo da labuta jogavam Capoeira vestidos com o mesmo traje usado na lida: calça com a boca alargada, camisa construída a partir de sacos de açúcar ou farinha do reino.

O apelido, de acordo com Medeiros (2016), é a identidade do capoeirista, a forma pela qual as pessoas o identificam no mundo da Capoeira. Tais codinomes podem emergir das aparências físicas, de alguma habilidade ou dificuldade, da terra natal, ou de inúmeros outros motivos. Para a autora, tal tradição (do apelido) teve origem no período em que a Capoeira era uma manifestação ilegal. Os capoeiristas apresentavam se as pessoas por apelidos com intuito de evitar inquérito policial. Na concepção de Medeiros (2016), o fato de não serem conhecidos pelos nomes reais evitariam delações, mesmo perante tortura.

As graduações também emergiram com base na roupagem dos negros. Um dos indumentos da veste era o lenço de esguião de seda que era colocado no pescoço, "cuja finalidade, dita por Mestre Bimba a Rego (1968), era evitar navalhada no pescoço, porque a navalha não corta seda pura, de que eram fabricados esses lenços importados" (REGO, 1968 p. 43).

Segundo Medeiros (2016) Mestre Bimba ao criar a Luta Regional Baiana, teria introduzido os lenços na Capoeira "para diferenciar seus alunos entre aluno formado, aluno especializado e mestre. Alunos novos não possuíam graduação" (MEDEIROS, 2016 p. 22). Para a autora, nos dias atuais é mais comum encontrarmos cordas amarradas nas cinturas dos capoeiristas, onde as diferentes cores simbolizam os níveis das graduações.

Já Paiva (2007), ao discutir a Capoeira Angola reitera que a referida prática corporal possui um sistema de graduação em três níveis: aluno, professor e mestre. $\mathrm{O}$ autor descreve tal prerrogativa a partir da narrativa do Mestre Boca Rica que salienta ter sido utilizado, pela velha guarda as denominações de aluno, contramestre e mestre, entretanto, ressalta que o contramestre, na atualidade pode ser o professor.

Outrossim, Vieira e Assunção (2008, p. 15) ao tecer considerações sobre a graduação na Capoeira mencionam que alguns grupos demarcaram um sistema de graduação sequencial de cores de cordéis ou graduações alternativas . Para os autores, esse processo de resgatar as "tradições afro-baianas começou a assumir papel importante, a ponto de alguns deles aproximarem-se da Capoeira angola. Isso coincidiu, é claro, com a revalorização da cultura afro-brasileira pela qual lutava o movimento negro". 
Já os instrumentos, foram introduzidos tendo a sonoridade adaptada aos golpes, promovendo uma ligação íntima (REGO, 1968). Para o autor, na atualidade, o Berimbau é o principal instrumento da Capoeira.

Segundo Conde (2007) existe três berimbaus compondo a roda da Capoeira: o Gunga; com uma sonoridade mais grave, responsável pela execução da base dos toques, tocado normalmente pelos mestres da roda; o Médio, detendo um som intermediário entre grave e agudo, incumbido pela base e poucas viradas no toque; e o Viola, emitindo um agudo em seu toque, caracterizado por muitas viradas ao tocar.

Existem diversos toques, cada um com sua função específica na roda, sendo o de Angola, aquele que direciona uma prática lenta, jogada em grande parte, com as mãos no chão, contendo mais encenações, e o São Bento Grande da Regional, utilizados para jogos velozes, objetivos, podendo ter acrobacias, os mais utilizados dentre os diversos grupos (CONDE, 2007).

O atabaque teve origem no oriente, sendo comum entre os persas e os árabes. Chegou ao Brasil trazido pelos portugueses, para ser usado em festas e procissões religiosas. Sua função na Capoeira é acompanhar por meio de marcações os toques dos berimbaus. Está presente nas rodas de Capoeira Angola, e nos dias atuais em algumas rodas da Capoeira regional. Entretanto, na Luta Regional Baiana, de Mestre Bimba, o atabaque não era utilizado (REGO, 1968).

O agogô é de origem africana, acredita-se que teve entrada no Brasil por meio dos negros (REGO, 1968). O autor relata ter presenciado o agogô em poucas rodas de Capoeira tendo a mesma função do atabaque, (acompanhar por meio de marcações os toques dos berimbaus). Também não existia na Capoeira do Mestre Bimba. Atualmente encontra se presente nas rodas de Capoeira, seja ela Angola ou Regional.

As Palmas, para Barbosa (2005), possuem relação com todos os instrumentos da roda e dialoga com a musicalidade. As palmas acompanham os toques dos berimbaus, com exceção do toque de Angola no qual tradicionalmente as palmas não se encontram presentes. As marcações das palmas são em alguns grupos em três batidas e, em outros quatro. Ambas as formas devem possuir harmonia com a cadência dos instrumentos (CONDE, 2007). Para o autor, as cantigas, forma pela qual são chamadas as músicas de Capoeira, acompanham quase todos os toques de berimbau.

Segundo o autor existem quatro tipos delas: a chula, música curta; o corrido, mais acelerado; a quadra que possui estrofe curta; e a ladainha, mais extensa e com o ritmo lento. Para Rego (1968) as cantigas são escritas e cantadas, a partir do enaltecimento de um 
capoeirista, narração de fatos da vida cotidiana: “[...] usos, costumes, episódios históricos, a vida e a sociedade na época da colonização, o negro livre e o escravo na senzala, na praça e na comunidade social" (REGO, 1968 p. 89).

Na concepção de Barbosa (2005) as cantigas são elementos que mediam as tensões, redirecionam a energia da roda e reconduzem os jogos. Para a autora, a mensagem emitida por meio da música, determina a construção da conversa apresentada pelos corpos nos movimentos dos jogadores e ainda servem "para determinar um espaço de mediação corporal e social, ajudam a definir a arte/filosofia do jogo e a sedimentar suas regras [...]” (BARBOSA, 2005 p. 95).

A roda de Capoeira, descrita por Conde (2007) de maneira objetiva, é caracterizada na forma circular com um diâmetro aproximado de três metros.

Para Guimarães (2012) a roda apresenta um caráter subjetivo que faz parte da composição da roda, a partir do ritual do ciclo de começo, fim e re-começo, um ambiente formado pelos corpos, um local que gera sentidos, que detêm uma simbologia possuidora dos significados. Tal subjetividade é fruto da intenção do capoeirista, não somente no jogo, mas ao compor a roda, cantar, tocar, ou mediante aos gestos corporais que podem servir como uma comunicação, entre os sujeitos da roda, e determinar o comportamento dos participantes (CONDE, 2007).

Assim, o jogo da Capoeira desenvolve-se na forma de dialogo entre os corpos, moldando se pela coreografia das palavras. "O êxito de cada jogada e do jogo como um todo depende da loquacidade corporal dos jogadores e da sua capacidade de ver a roda de Capoeira como um espaço de mediação corporal, linguístico e cultural” (BARBOSA, 2005 p. 79).

Apresentar tal cenário é fundamental, visto que para Goffman (2002) o cenário é o ambiente em que influencia na construção das representações coletivas.

Dessa forma, a fachada permite ao ator social escolher os elementos cênicos que a compõem e que permite a sua identificação no grupo, no caso específico da Capoeira, os elementos que compõem a ritualística da Capoeira, conforme descrito anteriormente.

\section{Resultados e Discussões}

Foi possível perceber a influência dos elementos que compõem a representação no episódio do caderno de campo, onde a fachada social referente ao cenário da Capoeira foi apresentada aos participantes do projeto: 
No primeiro momento aconteceu uma roda de conversa, a respeito de como proceder nas aulas: respeito, parceria, atenção e como acontecem alguns rituais da Capoeira (EPISÓDIOS DO CADERNO DE CAMPO, 09/03/2017).

Ao estabelecer o primeiro contato com os participantes do projeto, intencionalmente busquei informá-los sobre os valores que subjazem a roda de Capoeira: respeito mútuo, cooperação, solidariedade, disciplina para a construção do jogo, dentre outros.

Gostaria de ressaltar, conforme já mencionado na introdução do trabalho que nos aproximamos da Capoeira contemporânea, portanto, utilizamos no decorrer das aulas elementos da Capoeira Angola e Regional.

Assim, retomando a discussão sobre a fachada, para Pastinha (1988, p. 32), "a Capoeira exige certo misticismo, lealdade com os companheiros de "jogo" e obediência absoluta às regras que o presidem". Para o autor e Mestre, o capoeirista deve ter conhecimento, que a finalidade da Capoeira não é somente atacar e defender, mas, o desenvolvimento físico e mental do equilíbrio psicofísico, que o fará um exímio desportista, um sujeito dotado de autocontrole.

Um episódio anotado em caderno de campo que revela evidências da influência do cenário nas ações do projeto é:

\footnotetext{
Os estudantes chegaram eufóricos, e estimulados, dizendo ter praticado em casa os movimentos da Capoeira que aprenderam na aula anterior. Participaram da aula com bastante atenção. Surgiram perguntas a respeito dos apelidos. No decorrer da roda de Capoeira o estudante T.J questionou a razão pela qual os capoeiristas são conhecidos por apelidos E como se formava o sistema de graduações. (EPISÓDIOS DO CADERNO DE CAMPO, 16/03/2017).
}

Assim, ao final da aula, conforme a tradição das rodas de Capoeira, relembrei as falas do mestre Pastinha e uma passagem de sua $v_{i d a}^{4}$, na qual relatou ter sido convidado a tomar conta de uma casa de jogo. Ao chegar ao recinto, o dono da casa olhou para ele e perguntou seu nome, ele respondeu, eu me chamo Vicente Ferreira Pastinha. O proprietário era um policial no qual sabia das ocorrências de agressão naquela localidade partidas de um tal de Pastinha. Nesse momento Pastinha pensou: pronto estou preso (PASTINHA, 1969).

O parágrafo acima ilustra a identificação do capoeirista pelo apelido, visto que historicamente era uma prática não utilizar os verdadeiros nomes nas rodas de Capoeira pelo fato da Capoeira, até meados de 1933, ser considerada modalidade de malandros e ou 4 Depoimento obtido no LP Capoeira Angola Mestre Pastinha e sua academia.
https://www.youtube.com/watch?v=_UYOvyB7HNE. 
marginais. Assim, em caso de busca policial, a comunidade não sabendo o nome de registro dos capoeiristas, tornava-se difícil para as autoridades executarem uma prisão.

Com relação às graduações debrucei-me as discussões de Rego (1968) ao se referir ao mestre Bimba, que reitera a necessidade de identificar os alunos formados, especializados e mestre.

É possível perceber o entendimento do significado de tais elementos que constituem a fachada da roda de Capoeira, por meio das falas apreendidas na roda de conversa com os estudantes do projeto de Capoeira. No decorrer da conversa surgiu uma questão que provocou uma polêmica entre os estudantes, visto que o signo da graduação foi mencionado como uma referência para ser um capoeirista. A narrativa a seguir evidencia a explicação dos estudantes:

J. A - não. Porque eu ainda estou na primeira corda.

C. L- não. Porque estou começando. Só quando eu estiver podendo dar aulas de Capoeira.

M. E- não. Porque eu estou na primeira corda.

J. V- não. Estou na quarta corda, mas ainda não me considero.

T. J- não. Porque ainda tem muita coisa que eu não sei.

Y- Estou aprendendo ainda.

As narrativas apresentam posicionamentos diferenciados do que seria um capoeirista. O estudante $\mathrm{J}$. A. ressalta que a graduação, especificamente a corda o tornaria de fato capoeirista. Porém, C.L., M.E., T.J., Y, mencionam a necessidade de aprendizado antes de se tornarem capoeiristas. Pensando as narrativas explicitadas, apresentamos a discussão de Pastinha (1988) a respeito do que é ser capoeirista:

O capoeirista deve ter em mente que a Capoeira não visa, exclusivamente, preparar o indivíduo contra uma defesa ou agressão, mas, desenvolver, mais ainda, por meio de exercícios físicos e mentais um verdadeiro estado de equilíbrio psicofísico, fazendo do capoeirista o autêntico desportista. Um homem que sabe dominar-se antes de dominar o adversário (PASTINHA, 1988, p. 31).

Para o autor supramencionado, ser capoeirista é saber utilizar, com sabedoria, tudo aquilo que o cenário (ambiente) pode disponibilizar.

No intuito de apresentar evidências da Capoeira e a influência da fachada social e o influência na corporeidade - sendo está entendida como um processo de experiência do indivíduo e, em decorrência as marcas que apresenta em seu modo de pensaragir influenciadas pelo contexto histórico e social (NAJMANOVICH, 2001) -, apresento um episódio de aula que chamou a atenção dos(as) participantes da roda de Capoeira no dia 23/03/2017: 
No referido dia (23/03/2017) uma criança que participava das minhas aulas de Capoeira em outro espaço, acompanhou-me na aula do CIEP Costa Júnior, manifestando a curiosidade e comentários dos(as) estudantes na roda de Capoeira:

\section{V e A: ele é tão pequeno e já faz tanta coisa!}

Após o término da aula e durante uma roda de conversa com os(as) estudantes, TJ se manifestou salientando o comportamento e a postura do visitante. Considero relevante apresentar o episódio apresentado, pois revela a percepção dos(as) estudantes que não estavam habituados ao ambiente da roda de Capoeira, com relação a atitude, comportamento e interação do visitante na roda, portanto, a identificação de elementos que compõe a fachada da Capoeira. Cabe frisar que, os elementos simbólicos (GEERTZ, 1989) percebidos por TJ e os(as) outros(as) participantes permitiu a identificação do modus operandi da roda.

Para Goffman (2002) o participante escolhe os elementos cênicos responsáveis pela sua identificação no grupo. Assim, nos parece que o conhecimento das técnicas, habilidades, comportamentos e atitudes na roda, determinariam tal reconhecimento.

Cabe frisar que configurar a fachada das aulas, tornou-se fundamental, uma vez que o jogo da Capoeira, sua história e ritualística, fazem parte da estrutura que dão forma a tal cenário.

Outro momento que nos permitiu perceber o modo como os participantes do projeto concebem o cenário da roda foi a partir da discussão: o que é a Capoeira?

J. A - é para os escravos se defenderem.

T.J - é uma criação do mestre Bimba e uma luta para se defender dos brancos é também uma dança para esquecer o sofrimento. Na Capoeira a gente aprende a história.

As falas sobrepostas nos remetem ao elemento histórico que compõe a fachada da roda. Para Guimarães (2012), a Capoeira, assim conforme outras práticas populares realizamse por meio de um saber próprio do corpo. De acordo com o autor, tal saber guarda a lembrança ancestral, que permite sentir a temporalidade, no começo e recomeço da roda, fazendo o capoeirista sentir-se presente na história. Dessa maneira, é possível perceber uma transcendência de J.A e T.J quando dizem que a Capoeira é dos, ou para os escravos.

Conde (2007) descreve que ao se sentir parte do grupo, está estabelecida um meio de comunicação e entendimento entre os capoeiristas, promovido pela roda (fachada). 
As narrativas apreendidas na roda de conversa que revelam a importância do significado histórico para construção do entendimento da fachada da Capoeira e a escolha do papel social, emerge com o tema: Quando você chegou ao projeto, o que mais o chamou atenção?

\footnotetext{
A.V - quando fui à roda de Capoeira lá em Barra do Piraí.

J. A - as histórias da Capoeira e os mestres que você apresentou.

C.L - os mestres que a gente conheceu e das rodas em outros lugares que fomos com o senhor.

J.V- foi o aprendizado.

T.J - foi o dia que eu conheci o senhor. O dia que a gente aprendeu mais coisas. $\mathrm{O}$ senhor é bom capoeirista e bom professor, que ensina bem a gente.

Y - o tempo, que na Capoeira passa mais rápido.
}

A narrativa do(a) estudante "T.J" (O dia que a gente aprendeu mais coisas) remete se ao primeiro dia de aula de Capoeira. Procuramos, nesse dia, por meio de uma roda de conversa, apresentar o cenário que monta a fachada social da roda de Capoeira. Assim, utilizando a narrativa, extraímos as explicações para os demais elementos presentes na Capoeira, a partir das memórias (história).

A narrativa do(a) estudante A.V nos revela evidências sobre a fachada social, pois a estudante menciona o passeio dos(as) estudantes do CIEP Costa Júnior em Barra do Piraí, salientando a visita como um momento de aprendizado. A questão central revela-se na maneira como o grupo interagiu com o ambiente e com as pessoas que se dispuseram a recebê-los, visto que havia por parte das crianças uma observação atenta no modo de agir diante das ações que apresentavam: caminhada pelo campus do Centro Universitário Geraldo Di Biase, palestras, vídeos, lanche e a roda de Capoeira.

Para Guimarães (2012), é por meio das variedades de gestos coletivos e a maneira como são transmitidos, que a memória mítica é reatualizada em cada roda. Segundo o autor, esse saber (memória) permite nos dias atuais a propagação da Capoeira no mundo.

Outra evidência da roda de Capoeira com aspectos relacionados a fachada social e, em decorrência possíveis articulações nas relações dos estudantes, emerge na narrativa da mãe e da professora do estudante Q:

Mãe: Meu filho melhorou bem na escola. Depois que ele começou a fazer Capoeira, as notas dele estão bem melhores.

Professora: Q era aquele aluno inibido, não conversava com ninguém. Hoje é outro menino, ele quer participar, ele fala na aula, ele pergunta... 
Não estamos neste estudo preocupados com a melhoria da nota dos estudantes que participa do projeto, no entanto, este dado revelado pela mãe nos permite perceber que ocorreram mudanças significativas no comportamento de Q. O que buscamos ressaltar é que, apesar do aspecto quantitativo da nota nos aproximar da ideia de avaliação escolar que opera a partir da classificação, hierarquização, exclusão escolar, evasão escolar e ainda ao aspecto produtivista relacionado à nota, salientamos que no caso desse estudo, a avaliação significou a mudança na dimensão atitudinal do estudante, portanto, uma alteração de ordem qualitativa.

Na concepção de Falcão (2004) mudanças relacionadas aos aspectos atitudinais e comportamentais dos estudantes, podem influenciar significativamente em outros aspectos, no caso específico, a média da nota das provas. Segundo o autor, na Capoeira apesar de cada um ter uma maneira de interagir, a jogada é coletiva, isso requer a construção de um esquema mental, que resulta em uma lógica dinâmica e auto-organizativa dentro da cultura. Nessa trajetória, o autor ainda relata que essa forma de raciocinar, necessária na roda de Capoeira, já é por si só, uma auto-avaliação, relacionada à determinação social e econômica, que leva a reflexão do praticante a respeito dos "saberes/fazeres desta cultura, e a articulação de procedimentos pedagógicos para a superação de estágios de compreensão do senso comum a partir de aportes teóricos explicativos", obtidos por meio da reflexão dos diálogos acontecidos na roda de Capoeira (FALCÃO, 2004, p. 166).

A professora $\mathrm{G}$, nos apresenta outras pistas sobre mudanças nas relações com os estudantes, o espaço familiar e a escola. A narrativa da professora evidencia tal aspecto:

Professora G: Um dos meus alunos, o (C.L), é da Capoeira. Até então ele era muito largado, em relação a seu material e no estudo em sala de aula. Hoje, ele tem gabaritado várias matérias, leva o estudo a sério e organiza o seu material. Acredito que é um suporte do projeto que incentiva a ter disciplina, respeito, ordem, ter organização.

Segundo Perkov (2012), o processo de ensino aprendizagem, no caso específico da questão organizacional, é de percepção evidente no início da roda de Capoeira, no momento em que os mais experientes da roda, por meio dos rituais (formação da roda e os toques dos berimbaus), estabelecem uma ordem para os acontecimentos. Para o autor, tal fato se desenvolve por intermédio de um diálogo estabelecido na musicalidade, que prepara, contempla e media a reflexão do praticante, nos quais ouvem, processam e se organizam para responder de acordo com a etapa proposta, portanto, o cenário da roda (fachada) nos parece interferir nos processos para além da roda de Capoeira. 
Bertazzoli, Alves e Amaral (2008) ressaltam que a Capoeira se utiliza de diversos golpes e, as crianças e adolescentes têm prazer e curiosidade para aprender. Os autores ainda consideram que, em detrimento da espontaneidade, característica importante no jogo da Capoeira, a referida cultura corporal de movimento apresenta significativa potencialidade para a criação de novos golpes e, simultaneamente, estímulo a criticidade e resolução de problemas.

Portanto, a partir da experiência social estabelecida junto aos estudantes do CIEP Costa Júnior e enredado a noção de fachada social de Goffman (2002), percebemos que o cenário da roda de capoeira e toda a ritualística que a constitui, influencia significativamente no espaço em que se desenvolve, possibilitando aos atores sociais (professores, familiares e os próprios estudantes) re-significar o modo como interagem entre si e com o ambiente em que habitam, modificando sua representação social diante do mundo.

\section{Considerações finais}

Consideramos, mediante as discussões apresentadas, que os estudantes inseridos no Projeto Capoeira, ao perceberem os elementos que dão forma a fachada social da roda (instrumentos, musicalidade, coletividade, apelidos e o jogo) se sentem motivados em conhecer mais a respeito dessa cultura corporal brasileira.

As narrativas, ocorridas nas aulas, possibilitam o resgate das raízes históricas e das memórias dos mestres de Capoeira do passado, permitem momentos de lazer e reflexão a respeito da Capoeira, fortalece as relações em grupo, contribui para o respeito mútuo dos estudantes. Tais elementos, percebidos por meio das práticas cotidianas dos estudantes nas aulas de Capoeira, evidencia o papel estabelecido pelo Programa Arte, Educação e Cidadania.

Com relação à especificidade da roda de Capoeira, as investigações permitiram perceber que, ao identificarem a estrutura capoeirística, ocorrem mudanças comportamentais dos estudantes para permanecerem na roda: companheirismo, cooperação, paciência, hierarquia, autocontrole, disciplina, assiduidade, dinamismo e tomada de decisão. Tais comportamentos são evidenciados quando os participantes passam a adotar tais posturas durante a prática da referida cultura corporal de movimento.

Para finalizar, diante das narrativas apresentadas, foi possível perceber que as práticas e experiências obtidas na roda de Capoeira emergem em outros espaços, influenciando os processos de sociabilidade dos (as) estudantes, construindo com a construção de suas fachadas pessoais, idealizadas cotidianamente ao som dos berimbaus, do atabaque, dos 
pandeiros e, na composição do círculo que simboliza o começo, o fim e o recomeço da roda de Capoeira.

\section{Referências}

ALVES, N. Decifrando o pergaminho: o cotidiano das escolas nas lógicas das redes cotidianas. In: OLIVEIRA, I. B.; ALVES, N. (Org.). Pesquisa no/do cotidiano das escolas: sobre redes de saberes. Rio de Janeiro: DP\&A, 2001. p. 13-38.

AMOSSY, R. Imagens de si no discurso: a construção do ethos. $1^{\text {a }}$ Edição. São Paulo: Contexto, 2005.

DE ALMEIDA, J. A.; TAVARES, O; SOARES, A. J. G. A reflexividade nos discursos identitários da Capoeira. Revista Brasileira de Ciências do Esporte, v. 34, n. 2, 2011.

VIEIRA, L. R.; ASSUNÇÃO, M. R. Os desafios contemporâneos da Capoeira. Revista Textos do Brasil, v. 14, 2008. p. 9-19

BARBOSA, M. J. S. Capoeira: A gramática do corpo e a dança das palavras. Luso-Brazilian Review, v. 42, n. 1, p. 78-98, jun. 2005. ISSN: 0024-7413. Acesso em: 05 ago. 2017.

Disponível em: http://lbr.uwpress.org/content/42/1/78.short.

BENJAMIN, W. O Narrador: considerações sobre a obra de Nikolai Leskov em obras escolhidas magia e técnica, arte e política. São Paulo: Brasiliense, 1987. 221 p.

BERTAZZOLI, B. F.; ALVES, D. A.; AMARAL, S. C. F. Uma abordagem pedagógica para a capoeira. Movimento, v. 14, n. 2, p. 207-229, 2008.

CONDE, B. V. A Arte da Negociação: a Capoeira como navegação social. Rio de Janeiro: Novas Idéias, 2007. 136 p.

FALCÃO, J. L. C. Para além das metodologias prescritivas na Educação Física: a possibilidade da capoeira como complexo temático no currículo de formação profissional. Pensar a Prática: revista da pós-graduação em Educação Física/Universidade Federal de Goiás, faculdade de Educação Física, v. 7, n. 2, p. 155-170, 2004.

FERRAÇO, C. E. Eu caçador de mim. In Garcia, R. L. Método: pesquisa com o cotidiano. Rio de Janeiro: DP\&A, 2003. p. 157-175.

. Pesquisa com o cotidiano. Educação \& Sociedade. Centro de Estudos Educação e Sociedade, v. 28, n. 98, p. 73-95, jan./abr. 2007. Disponível em: http://www.cedes.unicamp.br. Acesso em: 24 set. 2017.

GEERTZ, C. A Interpretação das Culturas. Rio de Janeiro: Guanabara Koogan, 1989. 323 p.

GOFFMAN, E. Representação do Eu na Vida Cotidiana. 10ª . Edição. Petrópolis: Vozes, 2002. p. 233. 
GOULART, I. B.; BREGUNCI, M. G. C. Interacionismo simbólico: uma perspectiva psicossociológica. Em aberto, Brasília, ano 9, n.48, p. 51-60, out./dez. 1990. Disponível em: http://emaberto.inep.gov.br/index.php/emaberto/article/viewFile/1791/1762. Acesso em: 24 set. 2017.

GUIMARÃES, A. A. Capoeira: A Roda, O Jogo, O Ritual. In: BARRETO, M. A. S. C.; ANDRADE, P. G. R.; CUNHA JUNIOR, H. A.; RODRIGUES, A. (Org.). Africanidade (s) e Afrodescendência (s): perspectivas para a formação de professores. Vitória, ES: EDUFES, 2012. p. 169-179.

MEDEIROS, M.P.S. Capoeira: da Marginalização à Reafirmação Identitária. 2016. 55 f. (Trabalho de especialização do Curso de História e Cultura Africana e Afro-Brasileira) Universidade Federal do Rio Grande do Norte, Natal. 2016.

MOURA, A. F.; LIMA, M. G. A Reinvenção da Roda: Roda de Conversa, um instrumento metodológico possível. Revista Temas em Educação, v. 23, n. 1, p. 98-106, jan./jun. 2014. Disponível em: http://www.periodicos.ufpb.br/index.php/rteo/article/view/18338. Acesso em: 24 set. 2017.

NAJMANOVICH, D. O sujeito encarnado: questões para pesquisa no/do cotidiano. Rio de janeiro: DP\&A, 2001. 132 p.

PAIVA, IP de. A Capoeira e os mestres. 2007. 166 f. Tese (Doutorado em Ciências Sociais) Programa de Pós-graduação em Ciências Sociais, Universidade Federal do Rio Grande do Norte. 2007

PASTINHA, V. F. Capoeira Angola por Mestre Pastinha. $3^{\text {a} E d i c ̧ a ̃ o . ~ S a l v a d o r: ~ F u n d a c ̧ a ̃ o ~}$ Cultural do Estado da Bahia, 1988. 76 p.

Este Gungo é meu. In Capoeira Angola Mestre Pastinha e sua academia. Brasil: Gravadora Philips, 1969. Disponível em:

https://www.youtube.com/watch?v=_UY0vyB7HNE. Acesso em: 27/04/2018.

PELED, Y. Estados de performance na Capoeira. Educação Física em Revista, v. 2, n. 2, 2008. ISSN: 1983-6643. Disponível em: https://portalrevistas.ucb.br/index.php/efr/index. Acesso em: 18 set. 2018.

PERKOV, P. L. Capoeira: possibilidade de educação emancipatória junto a jovens de classes populares. 2012. 135 f. Dissertação (Mestrado em Educação) - Programa de PósGraduação em Educação. Universidade do Vale do Rio dos Sinos. São Leopoldo, RS. 2012.

PERTUSSATTI, M. Capoeira: diálogo de saberes como possibilidade de valorização da (s) identidade (s) afro-brasileira (s) e do patrimônio imaterial. RELACult-Revista LatinoAmericana de Estudos em Cultura e Sociedade, v. 03, p. 1-11, ed. especial, dez., 2017, artigo $\mathrm{n}^{\circ}$ 518. ISSN: 2525-7870. Disponível em:

http://periodicos.claec.org/index.php/relacult/article/view/518. Acesso em: 14 set. 2018.

Portal da United Nation Educational, Scientific and Cultural Organization (UNESCO). Capoeira torna-se patrimônio imaterial da humanidade. UNESCO Office in Brasília, 2014. 
Disponível em: http://www.unesco.org/new/pt/brasilia/about-this-office/singleview/news/Capoeira_becomes_intangible_cultural_heritage_of_humanity/.

Acesso em: 24 set. 2017.

Portal do Instituto Brasileiro de Geografia e Estatística (IBGE ${ }^{\mathrm{A}}$ ). Disponível em: http://cidades.ibge.gov.br/xtras/perfil.php?lang=\&codmun=330610\&search=rio-dejaneiro|barradopirai. Acesso em 05 de jul. 2017.

Portal do Instituto Brasileiro de Geografia e Estatística (IBGE $\left.{ }^{\mathrm{B}}\right)$. Disponível em: http://cidades.ibge.gov.br/xtras/perfil.php?lang=\&codmun=330610\&search=rio-de janeiro|valenca. Acesso em 05 de jul. 2017.

Portal do Instituto do Patrimônio Histórico e Artístico Nacional (IPHAN). Roda de Capoeira. Disponível em: http://portal.iphan.gov.br/pagina/detalhes/66. Acesso em: 06 set. 2018.

Portal do Ministério da Cultura. Convenção Sobre a Proteção e Promoção da Diversidade das Expressões Culturais. Disponível em: http://www.cultura.gov.br/politicas5//asset_publisher/WORBGxCla6bB/content/convencao-sobre-a-protecao-e-promocao-dadiversidade-das-expressoes-culturais/10913 Acesso em: 24 set. 2016.

REGO, W. Capoeira Angola Ensaio Sócio-Etnográfico. Rio de janeiro: Itapuã, 1968. 416 p.

ROSSINI, V.F. O conceito de papel social em Goffman. São Paulo: USP, 2013. 15p.

SALVINI, L; DE SOUZA, J; JÚNIOR, W. M. Entre fachadas, bastidores e estigmas: uma análise sociológica do futebol feminino a partir da teoria da ação social de Erving Goffman. Revista Brasileira de Educação Física e Esporte, v. 29, n. 4, p. 559-569, out./dez. 2015. ISSN 1981-4690: Disponível em: http://www.journals.usp.br/rbefe/article/view/108407. Acesso em: 07 set. 2017.

SILVA, R. A. Entre "artes" e "ciências": a noção de performance e drama no campo das ciências sociais. Horizontes antropológicos, v. 11, n. 24, p. 35-65, jul./dez. 2005. ISSN 18069983: Disponível em: http://www.scielo.br/scielo.php?pid=S0104$71832005000200003 \&$ script=sci_arttext. Acesso em: 06 set. 2017. 